\title{
ENTREVISTA COM SERGIO MICELI ${ }^{67}$
}

\author{
Lidiane Soares RODRIGUES* \\ Maria Eduarda da Mota ROCHA*
}

Contexto da entrevista

Esta entrevista foi realizada na residência de Sergio Miceli, em São Paulo-SP, na tarde de 30 de agosto de 2019, por Lidiane Soares Rodrigues e Maria Eduarda da Mota Rocha. Neste ano, o livro Intelectuais e classe dirigente no Brasil (1920-1945) resultado de seu doutoramento, realizado na França, no início dos anos 1970, sob a supervisão de Pierre Bourdieu - completou 40 anos de sua primeira publicação em Língua Portuguesa, na prestigiada Coleção Corpo e Alma do Brasil, da editora Difel ${ }^{68}$. Nossa conversa girou em torno da concepção, do conteúdo e da recepção deste livro (doravante, Intelectuais).

Maria Eduarda: Como você chegou ao tema dos intelectuais? Você não tinha pensado em estudar a cultura operária no doutorado?

\footnotetext{
67 Transcrição realizada por Paulo José de Carvalho Moura.

* UFSCar - Universidade Federal de São Carlos. Departamento de Ciências Sociais. São Carlos - SP Brasil. 13565-905 - lidianesrgues@gmail.com. http://orcid.org/0000-0003-2011-9888.

** UFPE - Universidade Federal de Pernambuco. Programa de Pós-Graduação em Sociologia. Departamento de Sociologia. Recife - PE - Brasil. 50670-901 - me.rocha@uol.com.br. https://orcid.org/0000-0002-3683-6614.

68 Sua primeira edição, em português: Sergio Miceli. Intelectuais e classe dirigente no Brasil (19201945). São Paulo: Difel, 1979. Dois anos depois, o livro foi publicado em versão compacta na França: Les intellectuels et le pouvoir au Brésil (1920-1945). Paris: Presses Universitaires de Grenoble/Maison des Sciences de l'Homme, 1981. Em 2001, juntamente com outros textos de Sergio Miceli sobre intelectuais, ele foi reeditado com o título de Intelectuais à brasileira. São Paulo: Companhia das Letras, 2001.
} 
Sergio Miceli: Sim, pensei assim em um momento, por causa do livro do Richard Hoggart $^{69}$. Mas nunca tinha feito pesquisa sobre o assunto, havia muita gente na faculdade que pesquisava a classe operária, e imaginei que seria difícil, que nunca havia realizado entrevistas. $\mathrm{O}$ tema dos intelectuais foi tomando corpo por meio da leitura de memórias e biografias. Era incrível que essa literatura, tão rica e com tamanha tradição no Brasil, nunca tivesse sido mobilizada para pensar a atividade intelectual. Fiquei absolutamente surpreso. Os livros de Pedro Nava, Manuel Bandeira, Taunay são por vezes citados, mas de forma sistemática, tais fontes nunca tinham sido utilizadas. Até mesmo antes de pensar nos casos, me interessei por esses gêneros memórias e biografias. Quando viajei para a França, em 1974, a pesquisa estava bem adiantada: já havia lido uma grande parte das biografias que usaria na tese. Levei muito material de pesquisa no avião. Quanto aos livros, muitos já estavam fichados. Desde o início, trabalhei com um questionário abrangente, um roteiro biográfico exaustivo. Além disso, já dispunha das nomeações, com ajuda de cinco pesquisadores remunerados pela Fundação Getúlio Vargas (FGV), onde eu trabalhava. Trabalhávamos todo dia na biblioteca municipal.

Lidiane Soares Rodrigues: Sergio, nossa prosa deseja abarcar três direções: as condições da concepção, os conteúdos e a recepção da tese. Então, ainda no que diz respeito à concepção dela, recuperei os nomes dos seus assistentes: Paulo Lolato, Ronaldo Bianchi, Rudolf Caio Petersen, Regina Reiss, Antonio Carlos Corsi Sachs e Afrânio Catani, que estará conosco na Sessão Especial da $\mathrm{ANPOCS}^{70}$. Eu gostaria de ouvi-lo a respeito do trabalho com esses assistentes e quais recursos a FGV oferecia aos docentes.

Sergio Miceli: Os assistentes trabalhavam bastante. Já imaginou levantar as nomeações de intelectuais durante quinze anos no Diário Oficial? É puxado! Eu não conseguiria fazer isso sozinho. Foram remunerados pelo Núcleo de Pesquisa e Publicações: um órgão com orçamento, secretária, sala; a chefia era um cargo eleito na congregação, havia disputa acirrada. E para nós de Ciências Sociais era importante, já para quem fazia Marketing não era muito relevante, porque dispunham de outras

69 Richard Hoggart. The uses of literacy, aspects of working-class life, with special references to publications and entertainements. London, Chatto and windus, 1957. Em português: Utilizações da cultura: aspectos da vida da classe trabalhadora, com especiais referências a publicações e divertimentos. Lisboa: Editorial Presença, 1973.

70 Quando realizamos a entrevista, nós, entrevistadoras, estávamos preparando nossa intervenção na Sessão Especial, "Um clássico há 40 anos: Intelectuais e classe dirigente no Brasil (1920-1945), de Sergio Miceli", realizada no 43 Encontro Nacional da Associação Nacional de Pós-Graduação e Pesquisa em Ciências Sociais (ANPOCS), na qual estariam também Afrânio Catani e André Botelho. 
fontes de recursos. Acessar e controlar esse dinheiro era valioso. Como conseguiria fazer a pesquisa, levantar dados sem dinheiro? As nomeações? Teria sido inviável. Havia também a Revista de Administração de Empresas, na qual atuei como redatorchefe e aí publiquei o debate sobre concentração e distribuição de renda, na época da ditadura, um tema polêmico. Agitei a FGV com essa publicação.

Lidiane Soares Rodrigues: E cavoucando esse núcleo, eu fui parar num texto seu sobre Gramsci. Confesso que achei inusitado: há trechos idênticos aos dos marxólogos típicos, há outros, contudo, em que claramente a leitura que o Bourdieu fez do Weber está orientando seu comentário sobre as organizações e os agentes (Igreja e partidos/ sacerdotes e líderes). Eu fiz uma cópia, li e reli, anotei, destaquei trechos típicos e atípicos de comentários de texto ao feitio marxologia, mas me pergunto: afinal o que lhe motivava nesse texto?

Sergio Miceli: Esse texto foi publicado na Revista de Educação de Campinas ${ }^{71}$. Antonio Gramsci é o grande autor da minha geração na pós-graduação. Quem fosse de esquerda e se interessasse pela área cultural tinha que dominar Gramsci, do contrário, nem entrava em aula. É um texto avantajado que fiz para o curso do Francisco Weffort. Eu me sentia instigado a demonstrar competência ao lidar com o marxismo, tinha que entrar na briga.

Lidiane Soares Rodrigues: A gente pode falar mais de marxismo depois? Voltando ao Intelectuais: no Brasil, a orientação formal foi do Leôncio Martins Rodrigues. Como você o conheceu?

Sergio Miceli: Em São Paulo. Sou carioca, não conhecia ninguém aqui, um adventício que deu certo na USP, um dos poucos... Ele era professor na pós-graduação e bem próximo dos alunos. Saia com a gente, tomava cerveja, e firmamos certa sociabilidade em conversas fora da faculdade que não tinham a ver apenas com a coisa intelectual, a gente se via muito. Depois, passei a frequentar a casa dele, conheci a mulher, Arakcy. Então, foi por aí. E propus o nome dele quando me desentendi com meu orientador, Luiz Pereira. Marialice Mencarini Foracchi, então a coordenadora da pós-graduação, aceitou embora soubesse que não era assunto de sua especialidade. Ele próprio estava ciente.

\footnotetext{
${ }^{71}$ Sergio Miceli. Gramsci: ideologia, aparelhos de estado e intelectuais. Reflexão - Revista do Instituto de Filosofia e Teologia. Campinas, n. 19, p.5-46, 1981.
} 
Maria Eduarda: Qual foi a importância do texto sobre os anatolianos, para a construção da tese ? $^{72}$

Sergio Miceli: Quando meu casamento ia desmoronar, quis voltar ao Brasil, mas Bourdieu condicionou o retorno à redação de um artigo a ser publicado na recém lançada Actes de la recherche en sciences sociales. Embora não tivesse nada rascunhado, ele sugeriu a escolha de um grupo de escritores atuantes no período anterior ao da tese em andamento a fim de testar minhas hipóteses. ${ }^{73} \mathrm{Na}$ hora da conversa, pensei nos pré-modernistas, pois era um grupo sobre o qual podia reunir rapidamente o material. Então, Sônia voltou com as crianças e fiquei lá mais cinco meses, salvo engano. Então, foi assim que elaborei o artigo sobre os anatolianos.

Lidiane Soares Rodrigues: Era um número da Actes de la recherche en sciences sociales (ARSS) dedicado à "crítica do discurso letrado", e o próprio Bourdieu tem um artigo notável sobre a "leitura de Marx". Mas é mesmo de arrepiar o diálogo do artigo do jovem Luc Boltanski com o seu, Sergio. O que você acha disso? ${ }^{74}$

Sergio Miceli: Então, houve cálculo do Bourdieu. Boltanski não se deu conta de imediato do que estava acontecendo. Mas Bourdieu fez de caso pensado. Boltanski tentou desencorajar Bourdieu por insistir que eu fizesse o artigo. Havia ainda certo receio de minha escrita em francês, claro.

Maria Eduarda: Francine Muel-Dreyfus mencionou em seu testemunho que esse texto teve impacto no grupo de pesquisa formado em torno de Bourdieu nos anos $1970^{75}$.

Sergio Miceli: Sim, foi chocante. $\mathrm{O}$ argumento era dissonante em relação, digamos, à doxa do grupo. O texto suscitou reação no grupo, na época; depois o pessoal incorpora e naturaliza. $\mathrm{O}$ que mais destoava era tratar do trabalho intelectual em conexão com o trabalho feminino, com o trabalho político do pai. O próprio Bourdieu me disse que havia repensado sua vida familiar de outro jeito, reconsiderando a relação com cada um dos três filhos, conforme as circunstâncias de cada gestação. Tal esquema

\footnotetext{
72 Sergio Miceli. Division du travail entre les sexes et division du travail de domination, étude clinique des anatoliens, au Brésil. Actes de la Recherche en Sciencies Sociales, v. 1, n. 5-6, 1975.

$73 \mathrm{O}$ entrevistado refere- se à Actes de la Recherche en Sciences Sociales, revista criada em 1975 por Pierre Bourdieu e seu grupo, como escoadouro preferencial para suas pesquisas.

74 Boltanski Luc. Pouvoir et impuissance. Actes de la Recherche en Sciencies Sociales, v. 1, n. 5-6, 1975.

75 Nós nos referimos à declaração feita no Colóquio Bourdieu et les Amériques, realizado pelo Institut des Hautes Etudes de l'Amérique Latine em Paris, nos dias 06 e 07 de junho de 2019.
} 
interpretativo não havia ainda surgido nesse feitio no interior do grupo de pesquisadores. Eles reagiram, não eram contra, mas se mostraram reticentes.

Maria Eduarda: Das cartas trocadas entre você e Bourdieu, inferi que você ia enviar os textos em português numa primeira versão, ele ia comentar e você redigiria em francês.

Sergio Miceli: Sondei a FGV sobre o custeio de uma tradução da tese. A tradução foi encomendada, mas ficou troncha, logo me dei conta de que não estava bem resolvida. Quando retornei a Paris, em fevereiro de 1979, fiquei até final de novembro redigindo o texto em francês; a defesa ocorreu em dezembro. Foi uma trabalheira infernal. Da tradução feita no Brasil, aproveitei alguns trechos que citavam material literário, os mais difíceis. Ele nunca discutiu o caso brasileiro, porque não conhecia, o que sempre estava em jogo era o andamento da argumentação. Os colegas do centro, quase todos, insistiram para eu tirar, e não tirei, a análise em torno do processo de feminização na raiz do trabalho intelectual. Diziam: "você vai levar a maior bronca, porque isso não existe na teoria, nunca se tratou disso...". Persisti: "mas isso está no material, não interessa se está ou não na teoria". Quando ele me devolveu o texto no dia seguinte, disse que estava ótimo. Então, vi que ele prestava atenção no que estava aprontando.

Maria Eduarda: O que você acha que Bourdieu incorporou de você?

Sergio Miceli: Acho que não incorporou nada. Eu era meio destoante dos outros orientandos, do pessoal da minha geração: Ana Maria Boschetti, Louis Pinto, Michael Pollack, Christophe Charle (que não fez com ele a tese, mas não saía de lá, era agregado) - , esse grupo que fez doutorado sob sua orientação - Marcel Fournier havia concluído a tese, quando cheguei. Todo o grupo estava exposto a esse Bourdieu anos 70 , exposto às leituras que ele achava importantes, às discussões que ele priorizava. Então, sinceramente, eu não queria discordar de nada, não tinha nenhuma pretensão, porque nem tinha capacidade, não queria fazer críticas, não era essa a pulsão. $\mathrm{Na}$ verdade, o material daqui evidenciava uma organização da vida intelectual muito diferente da francesa, não dava para ser de outro jeito e acho que ele foi atinando com as diferenças. $\mathrm{O}$ que ele reteve? Talvez esse modelo pretensamente universal tivesse que ser adaptado a outras experiências. Não era viável chapar o modelo em outro contexto. Quando a tese estava no final, fiz a exposição do argumento e reiterei não ser possível aplicar o conceito de campo onde não existia; havia espinha dorsal, claro, mas não um campo. Bourdieu assentiu. 
Maria Eduarda: Tanto na tese quanto no livro, você afirma que o seu objetivo não era testar modelo teórico. O que o motivava a fazer essa afirmação?

Sergio Miceli: Dizia isso para me defender. Porque logo me dei conta que o modelo teórico não se ajustava por inteiro ao material. No entanto, ele era a referência que eu mais admirava em termos de arrazoado argumentativo em sociologia. Quais as alternativas? Nós todos orientandos (Christophe Charle, Michael Pollak, etc.) tínhamos lido o que ele recomendava - Fritz Ringer, Edward Palmer Thompson e outros, mas tampouco podia transpor tais leituras ao caso brasileiro. Para os colegas europeus era mais fácil o diálogo, para mim, era mais complicado.

Maria Eduarda: Quais peculiaridades brasileiras não correspondem ao modelo?

Sergio Miceli: A mais relevante é o grau de imbricação entre a atividade intelectual e a política, bastante diverso do modelo francês. Até os que se diziam puramente letrados, os que proclamavam dedicar-se apenas à atividade intelectual, também tinham feito a carreira em meio ao cipoal da política. Isso não existia na França desse modo. A organização da vida intelectual é diferente aqui, não é a mesma tessitura institucional. E também era distinto o envolvimento dos intelectuais na imprensa. Havia tanta coisa singular, que não se podia transpor o modelo sem mediações.

Maria Eduarda: Então você acha que a noção de campo, que já pressupõe uma autonomia relativa, era mais problemática no caso brasileiro?

Sergio Miceli: Sim, bastante problemática. Como eu acho que no caso deles ocorre o contrário. Às vezes, eles acham que tem muita autonomia e tem menos autonomia do que eles imaginam.

Maria Eduarda: Ao mesmo tempo, a tese analisa um incipiente processo de autonomização do campo. Você concorda com essa leitura?

Sergio Miceli: Concordo, disso eu tinha clareza também. Minha dificuldade era aplicar assim ad hoc. Ele já tinha escrito alguns artigos sobre a vida intelectual, muito antes d'As Regras da arte $^{76}$. Muitos colegas imaginam que Bourdieu era um tipo dogmático. De modo algum, ele nos obrigava a ler autores que ofereciam um esquema de argumentação diferente do dele. As obras de Ringer ou de Thompson - não apenas o clássico em torno da classe operária, mas os trabalhos de história cultural, por

\footnotetext{
76 Dentre outros, destaca-se o artigo originalmente publicado na revista Les Temps Modernes, de JeanPaul Sartre, e editado em portugês como: Campo intelectual e projeto criador. In. POUILLON, Jean. Problemas do estruturalismo. Rio de Janeiro: Zahar, 1968.
} 
exemplo, o livro sobre William Morris ou os ensaios sobre os românticos ingleses são bastante distintos dos de Bourdieu. Ele admirava e recomendava esses autores, nós tínhamos que ler, embora não se encaixem de todo no seu feitio mental. A toada de que era intransigente não procede, ele sempre insistia no bordão de "deixar o material falar". Minha dificuldade era maior porque eu não tratava de uma experiência europeia, cercado de gente que só trabalhava casos europeus: Pollack estudava a Áustria, a República de Weimar; Louis Pinto, os filósofos franceses; Charle, as elites francesas (mais tarde, as europeias em prisma comparativo).

Lidiane Soares Rodrigues: E nenhum deles se valia de estatística, apenas de prosopografia? Eu queria ouvir você refletir um pouco a respeito dos métodos.

Sergio Miceli: Isso de estatística veio depois. Já a prosopografia, todos estávamos fazendo. Pinto estava aplicando aos filósofos, Pollack aos austríacos, todos estavam praticando de algum modo o método prosopográfico. Era um procedimento embutido no projeto de Bourdieu - As regras da arte também dependem de prosopografia, claro.

Lidiane Soares Rodrigues: Você localizaria em que momento essa necessidade de quantificar?

Sergio Miceli: É na geração da Gisèle Sapiro, com a análise de correspondências múltiplas. Bourdieu até começa a fazer isso antes, mas, inicialmente, os assistentes não estavam envolvidos. Por exemplo, A distinção. Esse livro está ancorado em material quantitativo; ele se aproximou de estatísticos, contratou alguns, para poder fazer análise de correspondências múltiplas ${ }^{77}$. Ele não era especialista, mas atinava com a importância da técnica. Ele deu partida e estimulou a conduta quantitativa, e o pessoal mais jovem - a geração de Gisèle Sapiro, Julien Duval, Frédéric Lebaron - começou a investir nessa pegada, já no final dos anos de 1980. Do grupo que trabalhava com ele, na época em que fiz meu doutorado, não me lembro de ninguém trabalhar com estatística. Os livros sobre a frequência aos museus e sobre os usos da fotografia ( $U n$ art moyen, L'amour de l'art $^{78}$ ) se valem de dados quantitativos, mobilizados em registro mais convencional.

Lidiane Soares Rodrigues: Eu gosto de apreciar a recepção de uma tese por meio das arguições que ela recebe. Por exemplo, investiguei como o "capital da leitura" de jovens leitores de Marx pôde ser sustentado diante das bancas avaliadoras de seus

\footnotetext{
77 Pierre Bourdieu. A distinção. Crítica social do julgamento. São Paulo/Porto Alegre: Edusp/Zouk, 2007. 78 Pierre Bourdieu. Un art moyen. Essai sus les usages sociaux de la photographie. Les Editions de Minuit, París, 1965. Pierre Bourdieu; Alain Darbel. L'Amour de l’art. Les Editions de Minuit, París, 1966.
} 
doutorados, que não tinham lido os mesmos textos que eles. Eu imaginei algo similar no seu caso - posto que você conhecia a teoria de Pierre Bourdieu e a adaptava, ao passo que seus interlocutores e avaliadores, no Brasil, não. Pergunto-me se as mudanças substantivas da tese para a publicação em livro deveriam algo a essa tensão entre o recurso intelectual (de quem inova) e o poder institucional (de quem avalia) no seu caso, tendo como documento cabal aquele Prefácio/arguição de Antonio Candido.

Sergio Miceli: É grande a diferença entre a tese e o livro. E não é só a diferença entre o livro e a tese: refiro-me também à diferença entre o livro francês (que oferece um texto mais condensado) e o livro brasileiro. Mas a edição de 2003 em português é a melhor. Não mexi no argumento, apenas em algumas frases, e ficou enxuto, bem trabalhado, pois eu tinha mais tempo na ocasião. Salvo engano, a tese comporta um capítulo sobre a igreja que foi compactado; Bourdieu insistiu em enxugar e juntar intelectuais católicos aos integralistas, em vez de pensá-los em separado. Além disso, como defendi a tese no Brasil muitos meses antes da defesa na França, inúmeras passagens caíram na versão francesa. A tese em francês é mais parecida com o livro em francês do que a tese em português com o livro em português. Ao retornar, aceitei o convite de Fernando Henrique Cardoso para publicá-la na coleção Corpo e Alma do Brasil da Difel. Tive alguns meses para retrabalhar o texto, demorei um bocado. Quis incorporar ao texto final acertos e mudanças suscitados pelas arguições, no Brasil e na França. A banca brasileira incluiu Maria do Carmo Campello de Souza (1936-2006), Gabriel Cohn, Antonio Candido, Luiz Carlos Bresser Pereira e Leôncio Martins Rodrigues, orientador. Maria do Carmo arguiu à revelia do espírito da tese, na linha dos estudos políticos, cobrando a ausência de Mannheim no trabalho. Na hora dei uma resposta atravessada, as pessoas riram, quis desqualificar o Mannheim. Bresser falou em seguida, em leitura bastante crítica do que já então me pareciam os pontos fortes e inovadores do trabalho, a começar pelas relações de gênero. No seu entendimento, a feminização não constituía uma dimensão relevante da atividade intelectual. A terceira arguição foi a de Antonio Candido, que já começou discordando, ao refutar o arrazoado e revalorizar os pontos rechaçados por Bresser: enalteceu o que havia sido desconsiderado. A arguição envolvia certa voltagem de testemunho: ele havia conhecido algumas das figuras mencionadas no trabalho e se mostrou um pouco chocado com a objetivação com que foram tratadas na tese. Houve um momento de descontração, porque ele começou a imitar algumas dessas pessoas, Fernando de Azevedo, Carlos Drummond de Andrade, entre outras. O salão nobre estava lotado; o público deu risada com o humor e a leveza da arguição. Mas de fato, eis o ponto 
crucial, ele desqualificou a arguição do Bresser. Gabriel Cohn adotou uma postura adorniana de viés clássico, mas retomou um ponto polêmico, ao externar opinião favorável ao partido que a tese adotara ao privilegiar a análise dos escritores em detrimento das obras: fechou a fala dizendo que o entendimento das obras estava subentendido no argumento, o qual encontrara, segundo ele, um modo original de encaixá-las na interpretação.

Lidiane Soares Rodrigues: Eu gostaria de ouvir você a respeito de uma questão disciplinar. Em primeiro lugar, há uma interlocução substantiva com trabalhos de pessoas que se estabeleceram como cientistas políticos: Maria Cecília Forjaz, Simon Schwartzman, Bolívar Lamounier. Além disso, você mira autores de referência para o pensamento político - notadamente, Raimundo Faoro e Sérgio Buarque de Holanda e relatou em outra entrevista que tinha sido convidado pelo pessoal da Ciência Política, para ir para essa área. Meus pontos: a diferenciação disciplinar era menos nítida? A qual clássico do pensamento brasileiro você ambicionava ligar sua tese?

Sergio Miceli: Eu tinha, e tenho até hoje, grande admiração por Faoro. Os donos do poder é um livraço, sensacional. Eu li a edição de $1974^{79}$. A obra costuma ser vista sob o prisma de uma análise cirúrgica do Estado, mas a força do livro está, a meu ver, no fato de empreender a história social da classe dirigente não-econômica brasileira, que ele designa como estamento. Há trechos estupendos de demonstração empírica. A discussão acerba em torno do livro deu origem a posturas antitéticas. Embora trabalhasse com objeto distinto, minha tese entabula um diálogo forte com Faoro, a conversa subentendida do livro. Com Simon Schwartzman, é diferente. Ele havia publicado São Paulo e o Estado Nacional, que suscitou debate intenso em nossa geração, pois frisava o fato de que a organização econômica, social e política de São Paulo tinha seguido um padrão diferente, menos dependente do Estado ${ }^{80}$. O que fazia sentido. Ele buscava uma especificidade morfológica na experiência política paulista e isso me fez pensar na especificidade do modernismo em São Paulo, em contraste com outros modernismos no país. Dialogo com essa perspectiva, não com o livro inteiro, pois o argumento guarda um vezo politicista do qual discordo. O livro foi muito lido e discutido pela minha geração. Quanto ao Sérgio Buarque de Holanda, não acho Raízes do Brasil tão sensacional como dizem; queria rechaçar o culturalismo da interpretação, mas sem me dar o trabalho de esmiuçá-la. Após a conclusão da tese, tive

\footnotetext{
79 A primeira edição do livro Os donos do poder, de Raimundo Faoro, datada de 1958, sofreu numerosas modificações em sua segunda edição.

${ }^{80}$ Simon Schwartzman. São Paulo e o Estado Nacional. São Paulo: Difel, 1973.
} 
a oportunidade de ler os trabalhos dele que me parecem decisivos, como, por exemplo, a análise do Império ${ }^{81}$. Mas o interlocutor de fundo é o Faoro. Maria Vitória Benevides me falou, faz tempo, que ele havia gostado do livro sobre os intelectuais.

Lidiane Soares Rodrigues: Vamos pensar juntos sobre a relação entre o seu mestrado e o doutorado? Eu percebo duas diferenças, além da óbvia, sobre os objetos. A primeira diz respeito à economia interna dos argumentos: em $A$ noite da madrinha ${ }^{82}$, tem uma força pulsante, de quando se é muito jovem, e não se faz questão de esconder as cutucadas polêmicas, para cada assertiva, puxa uma notinha e detona - Nelson Werneck Sodré, Frankfurt, Gramsci. No Intelectuais, é como se você estivesse explicitando menos contra o que você está tomando posição e sendo mais afirmativo. As controvérsias não se encontram no livro, mas na recepção dele e no histórico de suas respostas às críticas. Isso me leva à segunda diferença, a respeito da recepção. Você poderia falar um pouco sobre isso?

Sergio Miceli: Sim. Sabe o porquê dessa diferença? É que eu não tinha nenhum modelo sobre os intelectuais no Brasil, não havia nenhuma referência. Quando você entra em um assunto que dispõe de bibliografia considerável, você tem que dialogar. Faria diálogo com a história literária? Mas não estava fazendo história literária, nem crítica literária. Qual era o modelo dominante na faculdade? ${ }^{83}$ Fazia-se estética filosófica, crítica literária ou, digamos assim, uma história da arte formalista. Não estava fazendo nada disso. Logo, não teria como repetir o esquema combativo do mestrado. Não havia para quem atirar, eis o ponto. Na reedição d'A noite da madrinha, pensei em eliminar as rinhas de galo! Mas depois desisti. Queria enxugar, dar um tom mais sereno e olímpico, mas percebi que não era tão simples assim. As notas contra o Luiz Pereira [risos] me soam exacerbadas, provocaram rebuliço na faculdade.

Maria Eduarda: Ainda que sem o tom combativo, o questionamento sobre a ausência da análise de obras é respondido. Não é com Antonio Candido que você está dialogando?

\footnotetext{
$81 \mathrm{O}$ entrevistado refere-se à obra Do Império à República de Sérgio Buarque de Holanda, que faz parte da História Geral da Civilização Brasileira. Difel, 1972.

82 Sergio Miceli. A noite da madrinha. São Paulo: Companhia das Letras, 2005; Rio de Janeiro: Perspectiva, 1972.

$83 \mathrm{O}$ entrevistado refere-se à antiga Faculdade de Filosofia, Ciências e Letras (FFCL) da Universidade de São Paulo (USP), designada, após a reforma universitária de 1970 de Faculdade de Filosofia, Letras e Ciências Humanas (FFLCH).
} 
Sergio Miceli: Esse ponto daí entrou na tradição da sociologia da literatura. Nas referências da época - Levin Schücking (Sociologia do gosto literário, 1931), Alfred Von Martin (Sociologia do Renascimento), Lucien Goldman (Le Dieu Caché) - os desafios suscitados pela análise das obras eram formulados em chave distinta de como sucedeu mais tarde. Em Goldman, por exemplo, o pensamento de Blaise Pascal e as tragédias de Jean Racine são uma espécie de condensado da noblesse de robe, da mentalidade desse estrato. É um tiro de longo alcance, mas não se trata apenas de pura "análise de obra". Desde o início, eu não pretendia estudar as obras, queria compreender um grupo social, eis o foco da tese. Se persistisse em dar conta de tudo, perderia o eixo do argumento, que tem a ver com os intelectuais, e não com as obras. Há um pouco de análise de obras, meio de banda, acionadas para servir ao esclarecimento da trajetória dos escritores. O capítulo a respeito dos romancistas abriga alguma dose de análise de obras, pois tencionava explorar os nexos entre a escrita memorialística e s relatos ditos ficcionais, na medida em que os personagens como que retraduzem a história social dos narradores. É um equívoco ler esses escritores - José Lins do Rego, Graciliano Ramos, Raquel de Queiroz, Lúcio Cardoso -, como pura ficção. A tese se equilibra em argumento tríplice: as origens sociais e os embates familiares; as transformações em curso no mercado de trabalho intelectual; as relações dos intelectuais com a política. Nessa armadura de flancos combinados, varia a ênfase conforme o perfil dos grupos: os romancistas, os modernistas, a inteligência vinculada ao Estado.

Lidiane Soares Rodrigues: E os autores do pensamento autoritário...

Sergio Miceli: Tinha horror a privilegiar as figuras prestigiosas do pensamento autoritário, queria me desvencilhar de qualquer genealogia desse plantel. Trata-se de um objeto anacrônico, inventado a posteriori. As análises do dito pensamento autoritário elaboram tradições, dispensando por completo a história social dos autores. Como é possível falar de Manuel Bonfim, por exemplo, sem conhecer as circunstâncias de sua trajetória social, familiar, educacional e intelectual? Tampouco tinha interesse em lidar com os chamados figurões do pensamento social, outra linhagem fabricada por conta de embates entre correntes situadas em conjunturas recentes do campo intelectual. Não tinha interesse na abordagem livresca, na paráfrase de teses e de categorias em abstrato, ecoando a doxa intelectualista.

Maria Eduarda: Mas o Antonio Candido não era um refresco no ambiente da faculdade, uma alternativa de trabalhar a cultura que não fosse absorvida pela problemática de Gramsci e de Althusser? 
Sergio Miceli: Sim, por isso fui fazer o curso dele, com anuência do Florestan Fernandes que achou melhor transigir. Durou um ano inteiro, o primeiro semestre consagrado às teorias estéticas contemporâneas, o segundo às tragédias históricas do Shakespeare. Foi bárbaro, aprendi um bocado. Além da leitura das tragédias no original, lemos, estudamos vários obras de interpretação do dramaturgo, como os trabalhos de Tilliard e de Ian Kott. Gostei mais de Shakespeare do que de estética contemporânea, um blá blá blá inflado e pernóstico. Em conversa com Antonio Candido na primeira vez, para saber se podia fazer o curso, ele perguntou o que eu pretendia estudar e se não queria ir para teoria literária. Preferi continuar em sociologia, não me via crítico literário. Na época, fazer crítica literária era escolher um autor, empreender um trabalho monográfico, interpretativo. Como se livrar de tal armadilha à luz de tudo que veio depois? Mas não fiz com ele cursos sobre um determinado "autor", o escopo e o espectro de dimensões eram bem mais amplos. Candido lia as aulas previamente redigidas, lia tal como leu o texto de minha arguição; mas não era entediante, transmitia um cabedal formidável de erudição, sem pose, fiquei fascinado pela competência e pela originalidade do tratamento. Daí porque o convidei para minha banca de doutorado.

Maria Eduarda: Não só na banca, mas também como prefaciador. Olhando tanto tempo depois, como você vê o livro?

Sergio Miceli: O prefaciador era um cálculo político complicado. Decerto eu queria garantir um estribo de autoridade para o trabalho que me parecia arriscado em termos de recepção. Melhor alguém já familiarizado com o assunto. Eu não antevi o petardo que veio, mas acho que soube encarar. O livro está aí e teve uma vida instigante e fecunda. Talvez tenha resistido porque elaborou um argumento mais complexo do que a maioria dos estudos sobre a vida intelectual. Busquei empreender um modelo explicativo que mobiliza variados domínios da experiência, eis a força do livro. Mas a vida intelectual mudou por completo. Houve transformações de monta na vida intelectual: o peso crescente das universidades federais na expansão e diversificação do mercado de trabalho intelectual; o papel crucial das associações e sociedades científicas; o protagonismo das mídias impressas e eletrônicas, etc.

Maria Eduarda: Bom você falar nisso. Nós gostaríamos de saber por que você nunca mais voltou ao tema da indústria cultural?

Sergio Miceli: Mas eu voltei, meio encabulado. Escrevi sobre Roberto Carlos, sobre Ratinho, sobre colunismo social, tive uma coluna na Folha de São Paulo sobre futebol 
e esportes, durante meses, entre outros trabalhos. Bourdieu insistiu para eu escrever sobre futebol na ARSS. Eu ficava driblando. De fato, não voltei de maneira sistemática, mas não abandonei.

Maria Eduarda: Você identifica elementos autobiográficos no seu livro, na sua tese? Essa ideia do intelectual como sujeito que ocupa um lugar em falso no espaço social, tem a ver com sua história social?

Sergio Miceli: O que talvez seja autobiográfico, mas transformado e reprocessado, é o fato de que minha ligação com o mundo intelectual, desde criança, sucedeu pela mediação de meu tio materno, jornalista. Armando Miceli era redator-chefe do Correio da Manhãa, se casou já maduro, o que permitiu convivência próxima e prolongada com os sobrinhos. Os três sobrinhos homens, dois primos e eu, vivíamos vizinhos à casa da minha avó. Já casado, foi morar em Ipanema; minha avó vendeu a casa e continuou junto dele. Como eu era muito ligado aos dois, interessado pelo que escrevia no jornal, ia com frequência passar os finais de semana e parte das férias na praia. Também atuei como babá dos filhos dele, em especial de Maria, a mais velha; isso ajudava a viabilizar os programas noturnos do casal e de lambujem ganhava direito à conversa quando voltavam. $\mathrm{O}$ apartamento era muito frequentado por jornalistas e intelectuais ligados ao Correio da Manhã - Otto Maria Carpeaux, Antonio Callado, Moniz Viana, entre outros. Ficava ouvindo as conversas desse pessoal na sala; afora os drinques, também falavam um bocado de política. Meu tio escrevia a coluna política na segunda página do jornal, algo mágico para mim. Às vezes o texto saía assinado, outras não. Quando não vinha assinado, a brincadeira entre os sobrinhos era acertar o texto de sua autoria entre os sueltos da página. Foi assim que tomou corpo meu vínculo com o mundo intelectual e artístico. Como redator chefe, era muito ligado ao dono do jornal (Paulo Bettencourt) e à ex-mulher, Niomar [Moniz Sodré Bittencourt]. Lembro de vários telefonemas dele com colegas do jornal, mas também, a pedido de Niomar, de conversas com críticos de arte, mediando a negociação de obras para o acervo do Museu de Arte Moderna (MAM). Ele havia impulsionado a carreira como correspondente do Correio da Manhã no palácio do governo, no Rio de Janeiro; fora também um dos fundadores do Partido Socialista no Rio. Minha avó materna, imigrante calabresa, era uma pessoa inteligente, esperta, matreira, mas sem nenhuma instrução formal. Meu avô, mestre de obras na construção civil, morreu cedo; ela criou três filhas e meu tio com a renda do parco patrimônio herdado, o aluguel de casas em Santa Tereza. Era uma família de imigrantes italianos calabreses, distantes do universo cultural. Meu tio foi o primeiro a entrar na faculdade, tendo concluído o curso de direito. Meu pai provinha de uma família decadente do Vale do 
Paraíba, que também era distante da cena cultural. Ex-proprietários de terras na região de Quatis-RJ e de Barra Mansa-RJ, cidades mortas. Quatis é ainda hoje um pequeno reduto urbano que guarda vestígios da era de opulência. Mas eles perderam tudo, inclusive um hotel em Mendes-RJ, outra cidade próxima; então começaram a vender os bens. Quando menino, frequentei o casarão que ainda possuíam em Santa Teresa, quase uma chácara; o terreno ocupava boa parte do quarteirão. Lembro da cena de despedida do meu avô pouco antes de morrer, os netos em círculo ao redor da cama alta onde jazia estirado. Eu devia ter em torno de oito ou nove anos. A família de meu pai teve de se desfazer do patrimônio para sobreviver. A irmã mais velha arranjou emprego público, as outras irmãs se casaram, e meu pai acabou encostado em cargo público por intercessão do meu tio Armando. Eis o que enxergo de autobiográfico, mais a indagação de como alguém como eu se torna intelectual.

Maria Eduarda: Qual é a resposta que você construiu para você, Sergio?

Sergio Miceli: Eu não tinha muitas possibilidades. Meu pai havia perdido tudo; minha mãe dependia da ajuda do irmão, o tio que financiou minha vida para estudar em São Paulo. Embora desfrutasse de uma bolsa da CAPES, não era o bastante para viver aqui, alugar apartamento e demais despesas; ele me apoiou até eu arranjar o primeiro emprego, como docente no interior do estado. Como não havia mais recursos disponíveis, me vi arrastado aos estudos e ao vislumbre de uma carreira que não sabia bem como ia se viabilizar.

Maria Eduarda: E isso tem a ver com essa sua disposição em não brincar em serviço?

Sergio Miceli: Sim, porque ele me estimulou. Na verdade, ele achava que eu devia fazer direito. Como ele se tornou procurador do estado, conhecia a magistratura e acreditava poder me ajudar na carreira. Estudei apenas em escolas de elite - no Colégio de São Bento e no Colégio Andrews - tudo pago por ele. No Andrews, eu tive professores de Filosofia e de Sociologia no clássico, que me despertaram para assuntos novos. Comecei a me interessar por ciências sociais. Ele não foi hostil, mas achava Direito algo mais garantido. Diante de tais constrições, acabei mentindo para a família dizendo que faria o vestibular para Direito, mas havia feito inscrição para o exame de ingresso na Escola de Sociologia e Política, na Pontifícia Universidade Católica do Rio de Janeiro. Fui aprovado e me vi numa enrascada. Era perto do Natal e não sabia como teria coragem de dizer o que havia acontecido. Meu tio reagiu bem à notícia $\mathrm{e}$ 
me apoiou, a despeito de não imaginar, como disse, aonde isso ia levar. Concluída a graduação, quis fazer o mestrado, que ele também bancou.

Recebido em 20/09/2019.

Aprovado em 01/10/2019. 